\title{
Demographic Analysis of the China Mobile Apps Market for the Importance of Digital Economic Development in Indonesia
}

\author{
$1^{\text {st }} \mathrm{Y}$ Ying \\ Chinese Department \\ Faculty of Humanities \\ Bina Nusantara University \\ Jl. Kemanggisan Ilir III No. 45 Indonesia \\ yi_ying@binus.edu \\ $4^{\text {th }}$ Lohannes \\ Chinese Department \\ Faculty of Humanities \\ Bina Nusantara University \\ Jl. Kemanggisan Ilir III No. 45 Indonesia
}

\author{
$2^{\text {nd }} \mathrm{T} N$ Mursitama \\ International Relations Department \\ Faculty of Humanities \\ Bina Nusantara University \\ Jl. Kemanggisan Ilir III No. 45 Indonesia
}

\author{
$3^{\text {rd }}$ Shidarta \\ Business Law Department \\ Faculty of Humanities \\ Bina Nusantara University \\ Jl. Kemanggisan Ilir III No. 45 Indonesia
}

Abstract-Service business companies have also begun to shift their businesses to the Software as a Service (SaaS) platform. Physical books began to shift their form into electronic books (e-books) and conventional children's games began to shift to online games and mobile games. App Annie (a platform that analyzes the penetration of the mobile apps business in the world) publishes a research entitled "Retrospective: A Monumental Year for The App Economy" which writes research on the development of the mobile apps market in the world during 2017. Chinese market became the country with the fastest development of mobile apps in the world. Researchers want to know the trends of the mobile apps business in China as seen from the application category and the time of using apps. The data is expected to be a reference for Indonesian entrepreneurs who want to set up business using a mobile application. From the research data, it was concluded that the Application which was in the Industry Tag category, with 56,392 users, was the category with the most active users. Significant increase in mobile activity in this application occurs at 12 noon until 1 noon.

Keywords-Demographic, China Mobile Market, Digital Economic

\section{INTRODUCTION}

The crucial point of the mobile application market in the world is the level of internet penetration and the growth of mobile users in that area or country. Increasing internet penetration and the growth of mobile users each year are factors that are considered by the mobile application business. Both at the startup and corporate level, to continue to run the mobile apps business. Digitalization as an Innovative of business model has facilitated economic success. Business innovation is becoming an important tool in dominating markets for global competition [1] [2]. Some changes in this era can be seen from existing business trends. Offline retail companies are starting to shift their business to marketplace and e-commerce platforms. Service business companies have also begun to shift their businesses to the Software as a Service (SaaS) platform. Physical books began to shift their form into electronic books (e-books) and conventional children's games began to shift to online games and mobile games.

App Annie (a platform that analyzes the penetration of the mobile apps business in the world) publishes a research entitled "Retrospective: A Monumental Year for The App Economy" which writes research on the development of the mobile apps market in the world during 2017. This research shows that the Chinese market became the country with the fastest development of mobile apps in the world [3]. This is due to the rise of China's economic power with its economic growth over three decades, which makes China the driving force of the world economy [4]. The development of China mobile apps was followed by several other countries such as India, South Korea and Indonesia (Figure 1). 


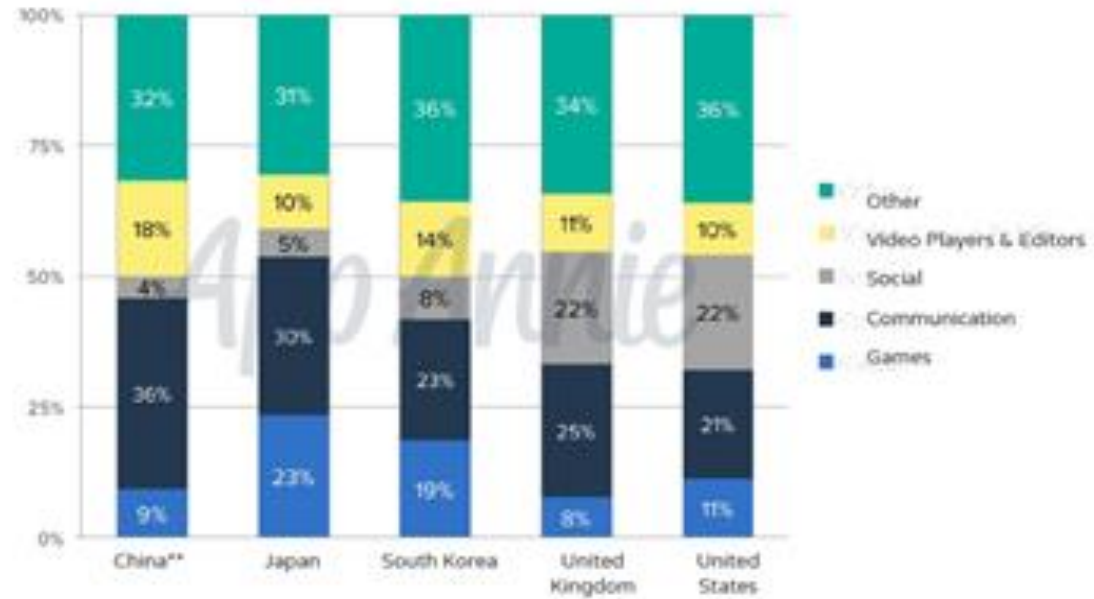

Fig. 1. Share of Time Chategory in Select Markets Androaid Phone, 2017

Sources: https://www.appannie.com/en/insights/market-data/app-annie-2017-retrospective/g.

With a population of 1.49 billion, with more than one billion mobile devices, China provides $\$ 1$ from every $\$ 4$ dollars generated globally throughout the apps store, in add apps, and mobile commerce. In Q4 2017, application users in China spent more than 200 billion hours on applications. With various aspects, China has a big opportunity in the era of mobile apps (Figure 2).

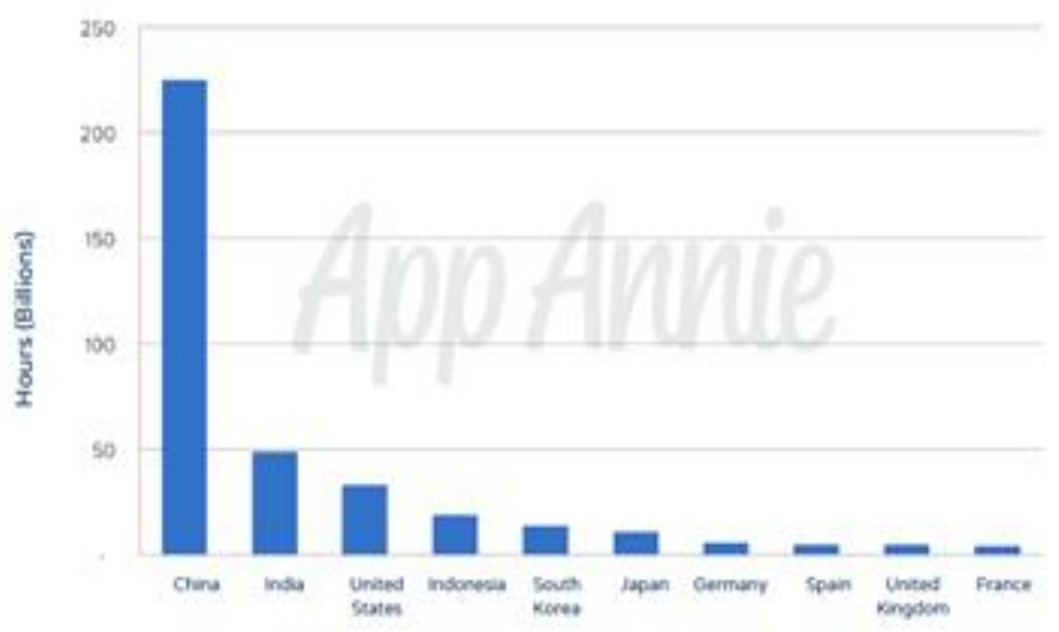

Fig. 2. Total Time Spent in Apps in Select Markets, Q4 2017

https://www.appannie.com/en/insights/market-data/app-annie-2017-retrospective

With the huge opportunities for startups in mobile apps in China, this research is carried out to find out the trends of the mobile apps business in China. This trend is seen from the genre of apps, application functionality, time of use of apps, and the number of active users that exist in each application (specifically for mobile apps services). After going through data analysis, this research will also conduct a comprehensive analysis of the comparison of trend apps in China and Indonesia, and will produce a comparison and probability whether Chinese startups have the opportunity to expand their business to Indonesia.

\section{LITERATURE REVIEW}

In the Annie App Retrospective Report 2018 [3], the global economic development of mobile apps in 2017, revealed that China is the largest application market in the world so far. China's application market is far higher than other countries. In Q4 2017, Chinese application users spent more than 200 billion hours on apps on iOS, Google Play and Android third parties (the second is much the same).

From the number of Month Active Users (MAU) in China, it was noted that the overall application of "Wechat" owned by Tencent became the highest application with MAU in China, followed by applications of QQ (Tencent) and Taobao (Alibaba Group), Alipay (Alibaba Group), and WiFi Master Key (Shanghai Lantern Network). From the games application, it was noted that Honor of Kings (Tencent) and Anipop (Happy Elements) managed to become the gaming application, with the most MAU, in 2017 (App-Annie, 2017).

The development and funding of the startup business to the unicorn level focuses on China. Grouping startups in China into 21 major groups namely: Agriculture, Automotive, Biotech \& Pharmaceuticals, Chemistry \& New Materials, Cloud, AI \& Big Data, Construction \& Real Estate, E-commerce, Education \& Training, Fintech \& Insurance, Food, Gaming \& entertainment, Greentech \& 
energy, Health products \& services, Intelligent hardware \& devices, Internet services, Logistics \& transportation,
Machinery \& instruments, Media \& marketing, Photonics \& optoelectronics, Retail, and IT \& telecom [5].

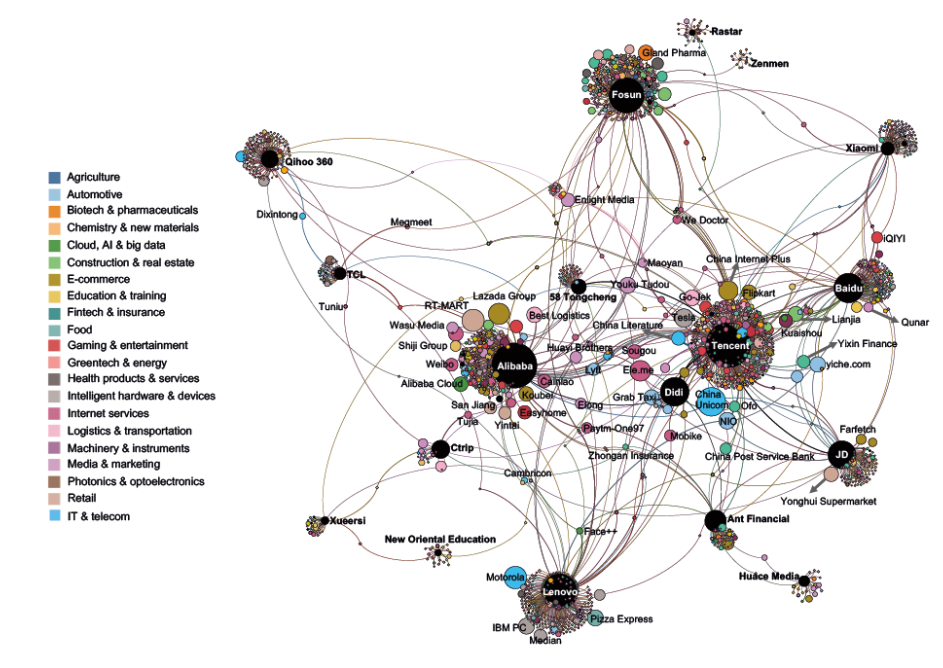

Fig. 3. China's Star-Up Landscape

Source: https://press.covestro.com/news.nsf/id/2018-177-EN/\$file/KAIROS_ENG.pdf

From the Mapping Group, a large grouping of startups up to the unicorn level in China, with several big names who lead in their respective fields, such as Tencent and Alibaba who lead as the two centers that oversee a variety of new and old startups. There are also several new names such as Ant Financial which leads in the fintech realm, Didi Chuxing and Meituan Dianping who lead in the ride hailing (Logistics \& transportation), JD and Taobao who lead in the e-commerce, and various other startups [3].

According to the Asset Management Association of China, in 2017, VC funds have increased to CNY 928 billion, with a growth rate of $50.41 \%$, compared to CNY 617 billion in 2016. According to the Ministry of Science and Technology, the number of $\mathrm{VC}$ investment institutions increased from 2045 to 2295 , with a growth rate of $12.2 \%$. As a result of active VC investment and an explosion in innovation and entrepreneurship, in January 2019, China owned 92 Unicorns and only came under the United States as the country with most Unicorns [6].

The grouping of product sales at the Fadhila Supermarket defines clustering or classification as a method used to divide data sets into groups based on predetermined similarities. Clusters are groups or groups of data objects that are similar to each other in the same cluster and dissimilar to objects in different clusters. Objects will be grouped into one or more clusters so that objects that are in one cluster will have a high similarity between one another [7].

\section{METHOD}

Data are collected from the TalkingData SDK, which is integrated in the TalkingData mobile application and it functions under the terms of service between TalkingData and the mobile application developer. Data are analyzed using Favorite Application Analysis, User Age Range Analysis and Application Active Hour Analysis.

\section{DISCUSSION}

TalkingData is a leading provider of third-party intelligence data solutions in China. With Smart DP as the core of its intelligence data application ecosystem, TalkingData empowers companies and helps them achieve data-based digital transformation [8].

TalkingData has built several large data and artificial intelligence laboratories, including a computing laboratory in Sillicon Valley and a computing laboratory in Beijing. TalkingData has also collaborated with the world's top universities and research institutions, including the MIT Media Laboratory, Stanford Artificial Intelligence Laboratory (SAIL), and Caltech Engineering and the Department of Applied Aerospace Science (GALCIT). TalkingData and its partners together accelerate the exploration and evolution of big data and technologies related to artificial intelligence. They also introduced international advanced technology to the fast-growing Chinese market, and encouraged the adoption of new technology in this growing industry.

A. Analysis of Categorized Applications in the Most Numbers of Active Users 


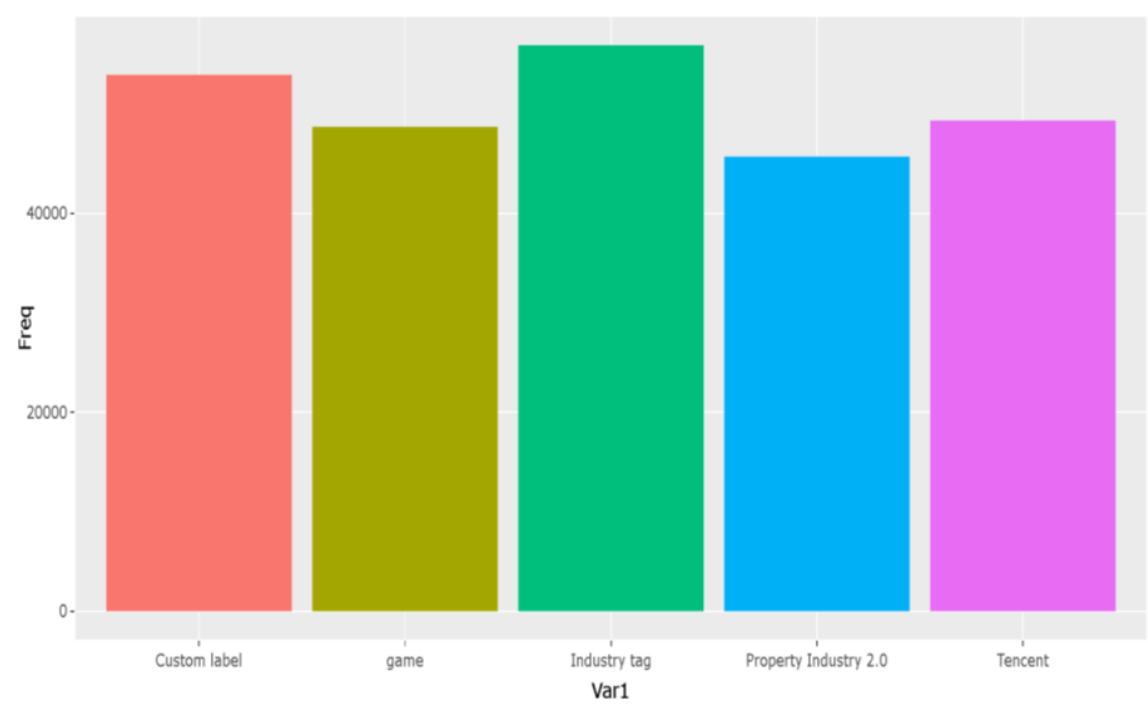

Fig. 4. Application Category Comparison

From the dataset, we get the results in the form of a bar plot that shows the application category with the number of most active users in the time the data was retrieved. The results show that the Tag Industry has the most active users, as many as 56,392, custom labels have 53,936 active users, tencent has 49,320 active users, the game has 48,707 active users and the property has 45,967 active users.

The existence of active users in the category of industry tags and property apps is a natural thing because in 24 hours, 8 hours is working hours, during these working hours, office applications or work-related applications have the most dominant active hours. These office applications vary greatly from HR applications (for example ,EKARI), accounting applications (Jojonomic, MYOB), communication applications such as Gmail and Slack, and other applications.
Custom labels (including other categories such as social media, ecommerce, saas applications, and other lifestyle apps), games, and tencent (including all the applications developed by tencent group) are applications that are active in user vacant times such as day and night. This interpretation will also be continued and strengthened in other interpretations.

B. Analysis of the most Specific Times of active Users

The graph or barchart shows the time in which there were found many active users (the chart above interprets and shows 6 time categories with the most active users). The results show that there was a significant increase at 12 to 1 $\mathrm{pm}$, also at $4 \mathrm{pm}$ to $5 \mathrm{pm}$ and a maximum increase at $7 \mathrm{pm}$ to $11 \mathrm{pm}$.

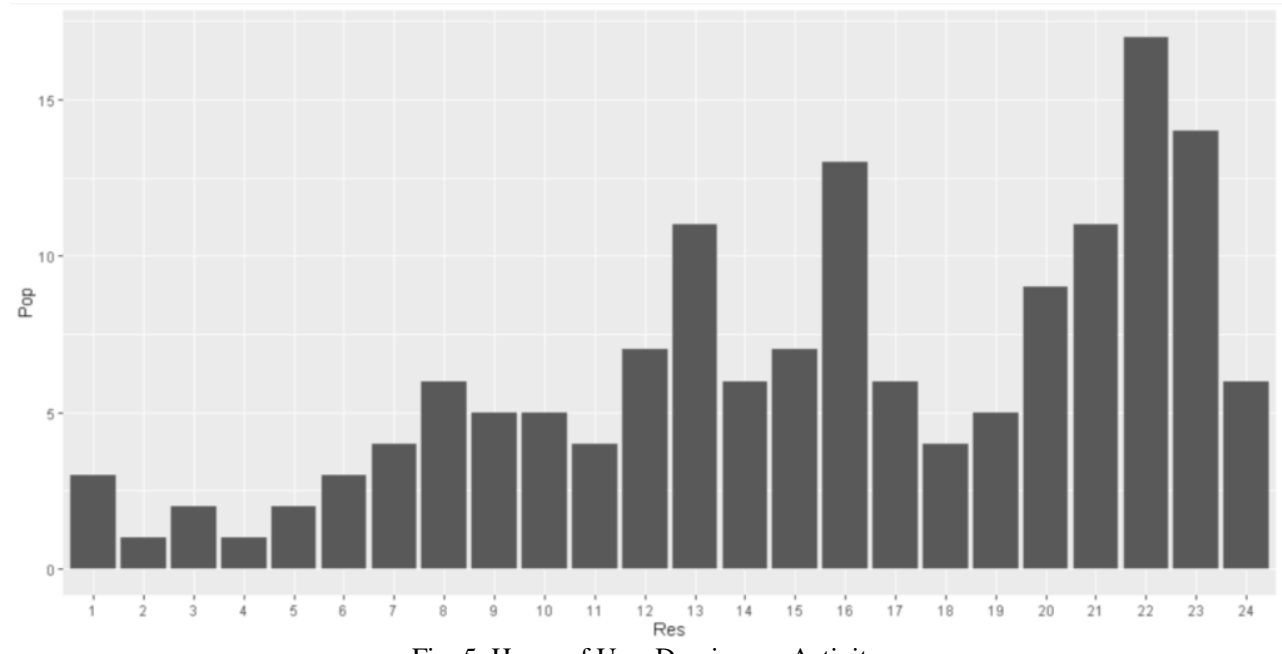

Fig. 5. Hours of User Dominance Activity

The increase in application users at 12 to $1 \mathrm{pm}$ occurred due to lunch break activities both in offices, schools and other activity centers. This lunch break is widely used by users to carry out their activities in applications, such as on social media networks, playing games, visiting other applications such as eccomerce, news applications, and other lifestyle applications. 
Significant increase also occurred in the range of $4 \mathrm{pm}$ to $5 \mathrm{pm}$ because users have ended their routines or activities in the office or school, and run other applications such as entertainment, games, and other lifestyle applications such as ordering taxis online, social media and eccomerce. The decline occurred at half past 6 in the afternoon until half past 7 in the evening, where at this hour, more offline activities were carried out such as sightseeing, or just to enjoy dinner.

Significant constant increases occur from $7 \mathrm{pm}$ to $11 \mathrm{pm}$, which at this time is the user's free time to carry out activities related to online applications, such as entertainment, social networking, doing other entertainment such as reading news online, playing games, ecommerce, watching the film and various other activities.

\section{CONCLUSION}

This study concludes that the application of Industry Tag with 56,392 users is the most active user. In addition, there was a significant increase in the level of activeness of mobile applications at 12 noon to $1 \mathrm{pm}$ and at $4 \mathrm{pm}$ to $5 \mathrm{pm}$. There is also a maximum increase from $7 \mathrm{pm}$ to $11 \mathrm{pm}$. From the results of the study, researchers suggest doing business in China by making applications in industrial categories or applications used by corporate (B2B applications). In addition, applications categorized as entertainment and lifestyle, such as custom labels and games, are advised to conduct market penetration or SEO marketing strategies at dominant hours such as 12 to $1 \mathrm{pm}$, and $4 \mathrm{pm}$ to $11 \mathrm{pm}$.

\section{ACKNOWLEDGMENT}

The authors gratefully acknowledge that the present research is supported by Ministry of Education Taiwan. The support is under the research grant Taiwan Studies Project of Year 2019.

\section{REFERENCES}

[1] Bleicer J and Stanley H 2018 Digitization as a Catalyst for Business Model Innovation Three-Step Approach to Facilitating Economic Success. Journal of Business Management 4 (2) 62-71

[2] Bereznoi A 2015 Business Model Innovation in Corporate Competitive Strategy. Problems of Economic Transition 57 (8) 14-33

[3] Sydow L and Cheney. S 20182017 Retrospective: A Monumental Year for the App Economy in App Annie 2017 Retrospective. https://www.appannie.com/en/insights/market-data/app-annie2017-retrospective/g.

[4] Ying Y, Mursitama T N, Theresia, and Mariana 2018 Welcoming Chinese investors in Indonesia: Improving the competency of professional Indonesian-Mandarin translator. IOP Conference Series: Earth and Environmental Science 126(1)

[5] Xu R 2018 “China's start-up landscape (and how to engage with it), Shanghai 2018". https://press.covestro.com/news.nsf/id/2018177-EN/\$file/KAIROS_ENG.pdf

[6] Zheng Y 2019 "Analysis on the Startup Accelerator Industry in China".

https://dspace.mit.edu/bitstream/handle/1721.1/122123/11193903 90-MIT.pdf?sequence $=1 \&$ isAllowed $=$ y

[7] Metisen D M and Sari H L 2015 Analisis Clustering Menggunakan Metode K-Means dalam pengelompokan Penjualan produk pada Swalayan Fadhila Jurnal Media Infotama 11 (2) 110-118

[8] TalikingData 2020 https://www.talkingdata.com/products.jsp?languagetype=en_us 